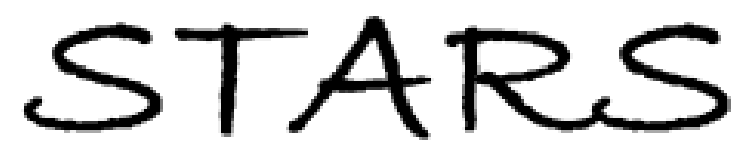

University of Central Florida

STARS

$1-1-2010$

\title{
Synergistic effect of carbon nanofiber and carbon nanopaper on shape memory polymer composite
}

\author{
Haibao Lu \\ University of Central Florida \\ Yanju Liu \\ Jihua Gou \\ University of Central Florida \\ Jinsong Leng \\ Shanyi Du
}

Find similar works at: https://stars.library.ucf.edu/facultybib2010 University of Central Florida Libraries http://library.ucf.edu

This Article is brought to you for free and open access by the Faculty Bibliography at STARS. It has been accepted for inclusion in Faculty Bibliography 2010 s by an authorized administrator of STARS. For more information, please contact STARS@ucf.edu.

\section{Recommended Citation}

Lu, Haibao; Liu, Yanju; Gou, Jihua; Leng, Jinsong; and Du, Shanyi, "Synergistic effect of carbon nanofiber and carbon nanopaper on shape memory polymer composite" (2010). Faculty Bibliography 2010 s. 467. https://stars.library.ucf.edu/facultybib2010/467

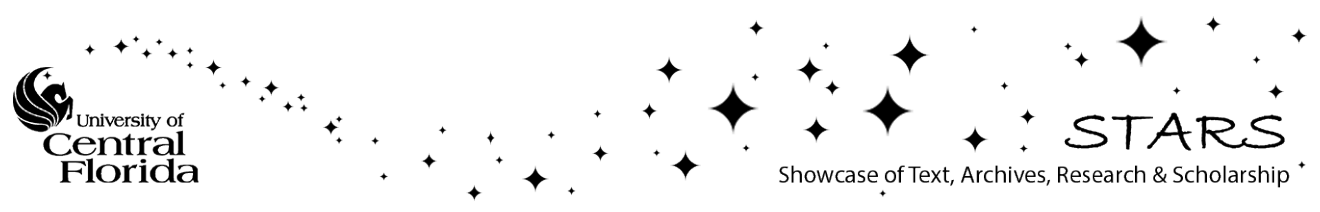




\section{Synergistic effect of carbon nanofiber and carbon nanopaper on shape memory polymer composite}

Cite as: Appl. Phys. Lett. 96, 084102 (2010); https://doi.org/10.1063/1.3323096

Submitted: 26 November 2009 . Accepted: 23 January 2010 . Published Online: 23 February 2010

Haibao Lu, Yanju Liu, Jihua Gou, Jinsong Leng, and Shanyi Du

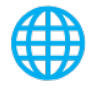

View Online

\section{ARTICLES YOU MAY BE INTERESTED IN}

Electroactivate shape-memory polymer filled with nanocarbon particles and short carbon fibers

Applied Physics Letters 91, 144105 (2007); https://doi.org/10.1063/1.2790497

Synergic effect of carbon black and short carbon fiber on shape memory polymer actuation by electricity

Journal of Applied Physics 104, 104917 (2008); https://doi.org/10.1063/1.3026724

Electrical conductivity of thermoresponsive shape-memory polymer with embedded micron sized Ni powder chains

Applied Physics Letters 92, 014104 (2008); https://doi.org/10.1063/1.2829388

\section{Applied Physics Reviews} Now accepting original research 


\title{
Synergistic effect of carbon nanofiber and carbon nanopaper on shape memory polymer composite
}

\author{
Haibao Lu, ${ }^{1,2}$ Yanju Liu, ${ }^{3}$ Jihua Gou, ${ }^{2, a)}$ Jinsong Leng, ${ }^{1, a)}$ and Shanyi Du ${ }^{1}$ \\ ${ }^{1}$ Center for Composite Materials and Structures, Harbin Institute of Technology, Harbin 150001, \\ People's Republic of China \\ ${ }^{2}$ Department of Mechanical, Materials and Aerospace Engineering, Composite Materials and Structures \\ Laboratory, University of Central Florida, Orlando, Florida 32816, USA \\ ${ }^{3}$ Department of Aerospace Science and Mechanics, Harbin Institute of Technology, Harbin 150001, \\ People's Republic of China
}

(Received 26 November 2009; accepted 23 January 2010; published online 23 February 2010)

\begin{abstract}
The present work studies the synergistic effect of carbon nanofiber (CNF) and carbon nanopaper on the shape recovery of shape memory polymer (SMP) composite. The combination of CNF and carbon nanopaper was used to improve the thermal and electrical conductivities of the SMP composite. The carbon nanopaper was coated on the surface of the SMP composite in order to achieve the actuation by electrical resistive heating. CNFs were blended with the SMP resin to improve the thermal conductivity to facilitate the heat transfer from the nanopaper to the underlying SMP composite to accelerate the electroactive responses. (C) 2010 American Institute of Physics.
\end{abstract}

[doi:10.1063/1.3323096]

Shape memory polymers (SMPs) are a class of unique macromolecules with an ability to memorize their permanent shape after undergoing a shape deformation. ${ }^{1,2}$ The molecular structure of SMP contains dual segments. One is highly elastic, and the other is able to remarkably reduce its stiffness in the presence of a particular stimulus. The latter segment can be either a molecular switch or a stimulus-sensitive domain. ${ }^{3}$ SMPs offer a number of advantages such as the controllable transition temperature of shape recovery, high capacity for elastic deformation (up to 200\%), easy processing, low density, low cost, and potential biocompatibility and biodegradability. ${ }^{1-5}$ The actuation of shape recovery of SMPs can be triggered by temperature heating, light, ${ }^{1,3}$ infrared light heating, ${ }^{5,6}$ electrical resistive heating, ${ }^{7-14}$ magnetic field heating, ${ }^{15-17}$ water, ${ }^{18}$ and solution. ${ }^{19-21}$ Extensive research have been done on conductive SMP composites by blending a small amount of conductive fillers such as carbon nanotubes, ${ }^{7,8}$ carbon black, ${ }^{9,10}$ electromagnetic particles, ${ }^{10,11}$ electrically conductive hybrid fibers, ${ }^{12,13}$ and continuous conductive carbon fibers. ${ }^{14}$ However, the resulting composites still could not achieve high electrical conductivity to meet the requirements. A high loading level of fillers is required to be blended into the SMP resin, which will introduce some processing challenges. The high viscosity of matrix will also make it difficult to have a uniform dispersion. ${ }^{22}$ A unique concept of making the nanocomposites from the nanopaper has been explored. Self-assembled CNF nanopaper is one of scaled-up materials that are important to enable multifunctional nanocomposites. ${ }^{23}$

The SMP (Veriflex ${ }^{\circledR} \mathrm{E} 2$, supplied from Cornerstone Research Group, Inc., Dayton, Ohio, USA) is an epoxy-based resin. The Veriflex E2 is a two-part, fully formable thermoset shape memory polymer (SMP) resin system. The cured Veriflex E2 resin has unique "shape memory" properties. When heated above the activation temperature $\left(T_{\mathrm{g}}\right)$, it changes from

\footnotetext{
a) Authors to whom correspondence should be addressed. Electronic addresses: jgou@mail.ucf.edu and lengjs@hit.edu.cn.
}

a rigid plastic to an elastic rubber. It combines shape memory properties with high toughness and good strength of epoxy. The SMP resin can change from a rigid glassy state to an elastic state when heated above certain temperature.

The as-prepared CNFs of $1.8 \mathrm{~g}$ were mixed with $600 \mathrm{ml}$ distilled water to form a CNF suspension. The nonionic surfactant $\mathrm{C}_{14} \mathrm{H}_{22} \mathrm{O}\left(\mathrm{C}_{2} \mathrm{H}_{4} \mathrm{O}\right)_{n}$ of $2 \mathrm{ml}$ was added to aid the dispersion of CNFs. The CNF suspension was sonicated with a high-intensity sonicator (MISONIX Sonicator 4000, Qsonica, LLC, Newtown, Connecticut, USA) at room temperature for $15 \mathrm{~min}$. After the initial sonication, both $\mathrm{CNF}$ suspension and probe were cooled down to room temperature. The sonication was performed again for another $15 \mathrm{~min}$ under the same condition. The CNF suspension was then filtrated through a $0.4 \mu \mathrm{m}$ hydrophilic polycarbonate membrane under a high pressure to make the nanopaper. After the filtration, the $\mathrm{CNF}$ nanopaper was dried in oven at $120^{\circ} \mathrm{C}$ for $2 \mathrm{~h}$ to completely remove water and surfactant.

The SMP resin was mixed with curing agent using a high shear mixer. The CNFs were blended into the SMP resin with different weight fractions $(0.5,1.0,1.5,2.0$, and $2.5 \mathrm{~g})$. The resulting mixture was degasified in a vacuum oven to completely remove air bubbles. In this work, resin transfer molding process was used to make the SMP composite. The nanopaper containing CNFs of $1.8 \mathrm{~g}$ was placed on the bottom of the mold. The SMP resin modified with CNFs was then injected into the mold. After the mold filling, the resin was cured at $120{ }^{\circ} \mathrm{C}$ for $24 \mathrm{~h}$ to obtain the SMP composite.

Scanning electron microscopy was used to study the structure of the CNF nanopaper, as shown in Fig. 1. The nanopaper has a porous structure with CNFs entangled with each other. The CNFs have a diameter ranging from 50 to $100 \mathrm{~nm}$. A network structure was formed by molecular interaction and mechanical interlocking between individual nanofibers. Such a continuous network made of individual CNFs will act as conductive path for electrons, which makes the nanopaper electrically conductive. The network structure depends on the quality of the dispersion of nanofibers. 


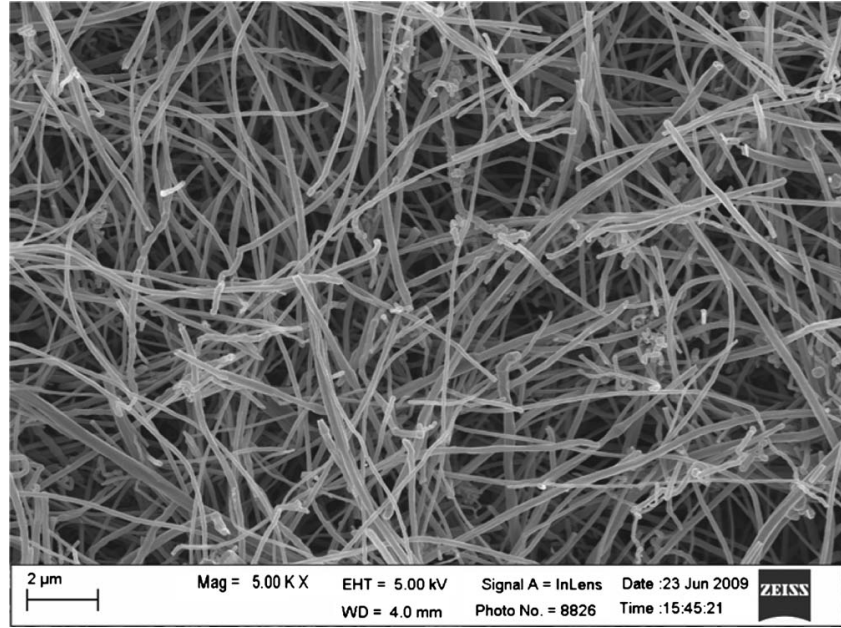

FIG. 1. Morphology and network structure of carbon nanopaper.

The electrical resistivity of the SMP composite was measured with the four-point probe method. The apparatus has four probes in a straight line with an equal interprobe spacing of $1.56 \mathrm{~mm}$. The radius of the probe needle is $100 \mu \mathrm{m}$. The electrical resistivities of the SMP composite samples blending different weight fractions of CNFs in the SMP resin were plotted against different locations, as shown in Fig. 2. All the composite samples were coated with one layer of carbon nanopaper containing $1.8 \mathrm{~g}$ CNFs. As the weights of CNFs blended into the SMP resin increased from 0 to $2.5 \mathrm{~g}$, the average electrical resistivity of composite samples decreased from 1.951 to $0.960 \Omega \mathrm{cm}$, respectively. The more CNFs were blended into the SMP resin, the more conductive paths were formed in the SMP composite. Given more conductive paths in one bulk, more electrons are involved in an electrical circuit. Therefore, the electrical current amplitude and current-carrying capability increases because more electrons are forced to pass through the cross section of the bulk. In addition, more conductive paths will increase the probability of forming relative shorter distances for the electron flow and the period of electron flow is significantly shortened.

All the SMP composites were coated with one layer of nanopaper containing $1.8 \mathrm{~g}$ CNFs through resin transfer molding process. Figure 3 shows the shape recovery of the composite specimen blended with $1.0 \mathrm{~g}$ CNFs in the SMP

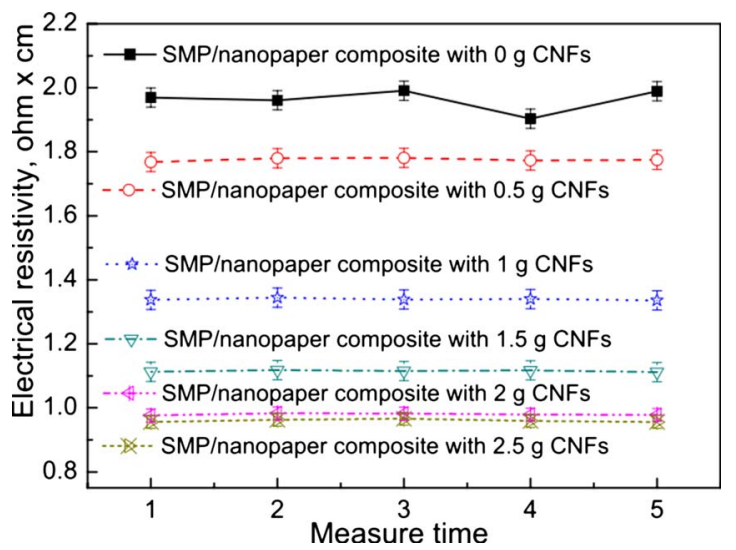

FIG. 2. (Color online) Storage modulus, loss modulus, and tangent delta curves for the SMP composites blended with various contents of CNFs.

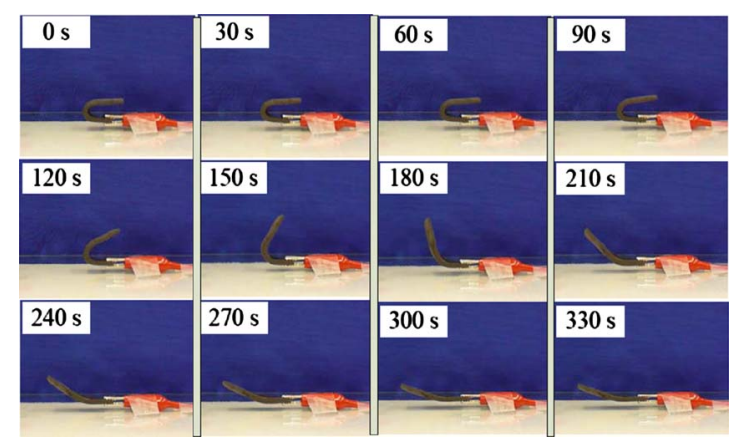

FIG. 3. (Color online) Series of photographs demonstrating the macroscopic shape memory effect of the SMP composite. The permanent shape is a flat strip, and the temporary shape is a right-angle shape.

resin. The flat (permanent shape) composite specimen with a dimension of $180 \mathrm{~mm} \times 12 \mathrm{~mm} \times 7.5 \mathrm{~mm}$ was bent as " $\mathrm{n}$ "like shape (temporary shape) at $150{ }^{\circ} \mathrm{C}$. This shape was kept until the specimen was cooled down to room temperature. No apparent shape recovery was found after the deformed specimen being kept in air for $2 \mathrm{~h}$. A constant $16.2 \mathrm{~V}$ direct current voltage was applied and an electric current of $0.05 \mathrm{~A}$ passed through the composite specimen. The shape recovery of the SMP composite specimen was recorded by a video camera. It can be seen that the SMP composite specimen took $330 \mathrm{~s}$ to complete the shape recovery. The specimen showed very little recovery ratio during the first 90 s. It then started to exhibit a faster shape recovery behavior until 240 s. During the last 90 s, no apparent change in the shape recovery was observed. Finally, it did not completely return to its original flat shape, which could result from the interfacial friction between the nanopaper and the underlying SMP composite. The SMP composite could not provide enough mechanical loading to pull the nanopaper to return to the original flat shape. In addition, the size of CNFs is in the same order as the typical segments of the SMP resin. The frictional interaction between the macromolecule segments and CNFs could reduce the shape recovery of the SMP composite.

The electroinduced shape memory effect of SMP composites was evaluated by shape recovery ratio as a function of shape recovery time. The shape recovery ratio refers to the shape recovery degree for the SMP composite specimen to return to its permanent shape from the temporary shape. The shape recovery ratio was determined by measuring the angle between the two sides of the bent specimen. The shape recovery time indicates the capability and speed of the SMP composite in response to external stimuli. It was determined by the time when the SMP composite returned to the permanent shape from the temporary shape. The flat composite specimen (permanent shape) with a dimension of $180 \mathrm{~mm}$ $\times 12 \mathrm{~mm} \times 7.5 \mathrm{~mm}$ was bent to a "n"-like shape (temporary shape) at $150{ }^{\circ} \mathrm{C}$ and remained this shape during cooling down to room temperature. The actuation of shape memory effect of the SMP composite was driven by an electrical current under a constant electric power of $0.8 \mathrm{~W}$.

As shown in Fig. 4, the composite specimen blended with $2.5 \mathrm{~g}$ CNFs in the SMP resin had the fastest response (it returned to the permanent shape within $186 \mathrm{~s}$ ) to the electrical stimulus. However, it has the lowest shape recovery ratio approximately to $83 \%$. On the other hand, the SMP composite blended with $0.5 \mathrm{~g} \mathrm{CNFs}$ had the slowest response 


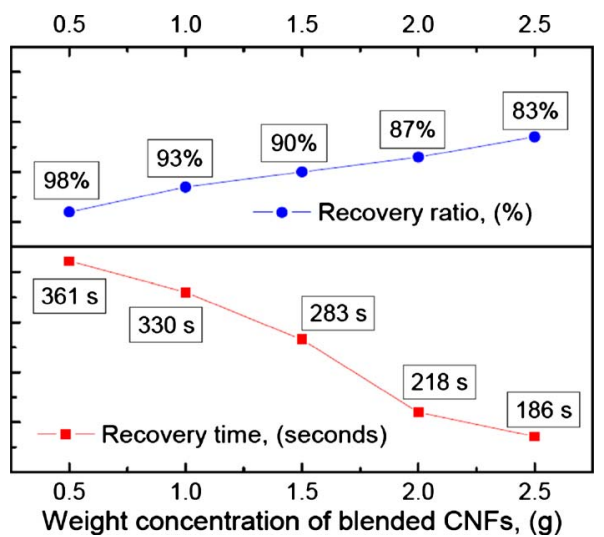

FIG. 4. (Color online) Shape recovery behavior of the SMP composites blended with various contents of CNFs.

to (it returned to the permanent shape within $361 \mathrm{~s}$ ), but the shape recovery ratio was approximately to $98 \%$. Therefore, the contents of CNFs blended into the SMP resin had a positive effect on the shape recovery speed but negative effect on the shape recovery ratio. A chemically cross-linked structure was formed by macromolecular chains during curing process of thermosetting SMP resin. The relative motion of macromolecule segments or chains is the primary mechanism of shape memory effect. During the process of shape recovery, the packed macromolecular segments needed to overcome external constraints to return to the permanent shape. CNFs do not have shape memory effect and they cannot return to the original configuration by themselves. They need a recovery force provided by the SMP macromolecular segments to get back the original configuration. The opposite motion between CNFs and SMP macromolecular segments results in an interfacial friction. The SMP macromolecule segments have low recovery force to overcome the loading from CNFs. Therefore, the SMP composite has a relative lower shape recovery ratio compared to the pure SMP resin. The shape recovery ratio decreased with the contents of CNFs blended into the SMP resin. However, these CNFs could significantly improve the thermal conductivity of the SMP composite to facilitate the heat transfer from the nanopaper to the underlying SMP composite. Therefore, the speed of electroactive response significantly increased with the contents of CNFs in the SMP composite.

A series of experiments were conduct to study the synergistic effect of carbon nanofiber and carbon nanopaper on the shape recovery of the SMP composites. The actuation of the SMP composites was achieved by the electrical resistive heating of carbon nanopaper. The thermal and electrical properties of the epoxy-based SMP resin were improved by blending conductive CNFs. The electrical resistivity of the SMP composite is $10^{16}$ times lower than the pure SMP resin by coating a nanopaper containing $1.8 \mathrm{~g}$ CNFs. In addition, the electrical resistivity of the SMP composite could be further lowered down from 1.954 to $0.96 \Omega \mathrm{cm}$ by blending $2.5 \mathrm{~g}$ CNFs into the SMP resin. These CNFs also significantly improved the thermal conductivity to make the SMP composite have a fast response to electrical resistive heating. However, the shape recovery ratio was reduced due to the interfacial friction among the SMP macromolecular segments, carbon nanopaper, and blended CNF particles.

The materials presented here are based upon work supported U.S. National Science Foundation under Grant No. CCMI-0757302. Any opinions, findings, and conclusions or recommendations expressed in this material are those of the authors and do not necessarily reflect the views of U.S. National Science Foundation.

${ }^{1}$ A. Lendlein, H. Jiang, O. Jünger, and R. Langer, Nature (London) 434, 879 (2005).

${ }^{2}$ J. S. Leng, H. B. Lu, Y. J. Liu, W. M. Huang, and S. Y. Du, MRS Bull. 34, 848 (2009).

${ }^{3}$ A. Lendlein and S. Kelch, Angew. Chem., Int. Ed. 41, 2034 (2002).

${ }^{4}$ P. T. Mather, X. F. Luo, and I. A. Rousseau, Annu. Rev. Mater. Res. 39, 445 (2009).

${ }^{5}$ H. Koerner, G. Price, N. A. Pearce, M. Alexander, and R. A. Vaia, Nature Mater. 3, 115 (2004)

${ }^{6}$ J. S. Leng, X. L. Wu, and Y. J. Liu, J. Appl. Polym. Sci. 114, 2455 (2009).

${ }^{7}$ Y. J. Liu, H. B. Lv, X. Lan, J. S. Leng, and S. Y. Du, Compos. Sci. Technol. 69, 2064 (2009).

${ }^{8}$ J. W. Cho, J. W. Kim, Y. C. Jung, and N. S. Goo, Macromol. Rapid Commun. 26, 412 (2005).

${ }^{9}$ J. S. Leng, X. Lan, Y. J. Liu, and S. Y. Du, Smart Mater. Struct. 18, 074003 (2009).

${ }^{10}$ J. S. Leng, W. M. Huang, X. Lan, Y. J. Liu, and S. Y. Du, Appl. Phys. Lett. 92, 204101 (2008).

${ }^{11}$ J. S. Leng, X. Lan, Y. J. Liu, S. Y. Du, W. M. Huang, N. Liu, S. J. Phee, and Q. Yuan, Appl. Phys. Lett. 92, 014104 (2008).

${ }^{12}$ J. S. Leng, H. B. Lv, Y. J. Liu, and S. Y. Du, Appl. Phys. Lett. 91, 144105 (2007).

${ }^{13}$ J. S. Leng, H. B. Lv, Y. J. Liu, and S. Y. Du, J. Appl. Phys. 104, 104917 (2008).

${ }^{14}$ X. Lan, Y. J. Liu, H. B. Lv, X. H. Wang, J. S. Leng, and S. Y. Du, Smart Mater. Struct. 18, 024002 (2009).

${ }^{15}$ H. B. Lu, Y. J. Liu, J. Gou, J. S. Leng, and S. Y. Du Int. J. Smart. Nano Mater. 1, 1 (2010).

${ }^{16}$ P. R. Buckley, G. H. McKinley, T. S. Wilson, W. Small, W. J. Benett, J. P. Bearinger, M. W. McElfresh, and D. J. Maitland, IEEE Trans. Biomed. Eng. 53, 2075 (2006).

${ }^{17}$ G. Vialle, M. Di Prima, E. Hocking, K. Gall, H. Garmestani, T. Sanderson, and S. C. Arzberger, Smart Mater. Struct. 18, 115014 (2009).

${ }^{18}$ W. M. Huang, B. Yang, L. An, C. Li, and Y. S. Chan, Appl. Phys. Lett. 86, 114105 (2005).

${ }^{19}$ J. S. Leng, H. B. Lv, Y. J. Liu, and S. Y. Du, Appl. Phys. Lett. 92, 206105 (2008).

${ }^{20}$ H. B. Lv, J. S. Leng, Y. J. Liu, and S. Y. Du, Adv. Eng. Mater. 10, 592 (2008).

${ }^{21}$ H. B. Lu, Y. J. Liu, J. S. Leng, and S. Y. Du, Smart Mater. Struct. 18, 085003 (2009).

${ }^{22}$ J. Gou, Polym. Int. 55, 1283 (2006).

${ }^{23}$ N. A. Koratkar, B. Wei, and P. M. Ajayan, Compos. Sci. Technol. 63, 1525 (2003). 